\title{
3. Social Variability in Retirement Behaviour: An Analytical Framework
}

The following sections set out the analytical bases of this study. Drawing on the plurality of contributing factors identified in the literature, the first sections (3.1.1-3.1.5) develop a theoretical framework of individual action in retirement. It will serve as a conceptual guideline in the empirical examination of the workretirement nexus at the individual level.

Secondly, I discuss the comparative dimension of the research design. At the macro level, the well-known welfare-regimes typology will be used as a heuristic metric of institutional configurations that can explain international differences in retirement ages. Moreover, a set of micro-macro mechanisms is introduced that help to establish the linkage between country-level factors and individual variation in retirement behaviour.

\subsection{A Life Course Stratification Approach}

The controversial debate about the respective role of push and pull factors in early exit from work, summarised in the previous chapter, has ended in a draw. At this stage there is little doubt left that both financial incentives and labour market constraints exert an important impact on the timing of retirement. There is not much added value in further attempting to determine which of the two dimensions is, overall, more influential. Instead, the theoretically pertinent questions have become: Which social groups are more susceptible to financial incentives of prolonged work? Which social groups are at greater risk of being forced into early retirement?

I propose to tackle these questions with an approach that adopts sociological life course theory and class analysis as its main conceptual pillars. Whereas life course theory allows the analyst to account for norms of aging, class analysis reminds us that also in retirement, life chances are unequal. Standing in the tradition of empirical micro sociology, this study embraces an approach in accordance with the premises of the social-mechanisms paradigm (Hedström \& Swedberg 1998), methodological individualism (Boudon 2003) and comparative life course research (Mayer 1997).

To begin with, the case shall be made that an adequate analytical account of retirement behaviour needs to take account of heterogeneous retirement preferences, which are essentially a function of individual work experience. In the subsequent section, I revisit the life course approach in search of an appropriate conceptualisation of age norms within an individual-centered theoretical approach to retirement timing. Following on from this, I use class

(cc) BY-NC-ND 
and gender theory to emphasise the role of unequal opportunities in retirement transitions. Moreover, based on recent developments in stratification theory, I will argue that the scope of social class and gender theoretically reaches even further, potentially modifying the very configuration of individual preferences.

The fourth section draws on life course theory to suggest a set of mechanisms by which family processes influence retirement decisions. Finally, in the synthesis section, I attempt to assemble the various conceptual pieces into a coherent theoretical model of individual agency in retirement. Although they have been rarely applied jointly in retirement research thus far, stratification theory and the life course approach are compatible, and even turn out to be complementary when it comes to explaining social variability in the timing of work withdrawal.

\subsubsection{Work Orientations}

Understanding the social mechanisms at work in retirement transitions from a sociological perspective requires prior theorising on the plural motivations for retirement. It seems obvious that people's preferences for work and leisure are significant in their retirement decisions. Nonetheless, individual orientations towards work have largely been neglected in the relevant literature. Indeed, push and pull theories rest on diametrically opposed assumptions with regard to the retirement preferences of individual actors. These assumptions are often only implicit and lead to ignoring potential sources of heterogeneity in work orientations. While economists stick to the idea that people would, in principle, prefer not to work, gerontologists like to assume that most early retirees would have preferred to work longer. In order to better understand the dynamics of labour market withdrawal, we shall first ask why people work.

In economics, work is regarded as instrumental. Homo economicus only works for the money. Consumption is his final purpose because it yields utility, whereas work is not more than a means to generate the required income. Although the economic doctrine by necessity has little to say about the origin of preferences, work is conventionally regarded as a "bad" that lowers utility (Arnds \& Bonin 2003). This is a consequence of the set-up of standard econometric models (see section 2.2). Mostly it is simply presumed that "if they aren't paid, people don't work" (Gruber \& Wise 2004b: 1).

In contrast, the sociological perspective typically assumes an intrinsic value of work in modern societies (Doherty 2009; cf. section 2.4). This modern work ethic, which has religious origins (Weber 2000 [1904/05]), is rooted in the conviction of the value of the specific work per se. Svallfors (2006: chap. 3) presents findings that corroborate the claim that there is a normative attachment to employment. Non-financial employment commitment is remarkably widespread. In fact, only 
$18 \%$ of Swedish respondents agreed that "a job is just a way to earn money - no more." In comparison, the maximum average score on that item was reached in Britain, with 34\%. Further, three quarters of Swedish and German respondents claimed that they would enjoy having a paid job even if they did not need the money. Even in Britain, where the most pronounced instrumental work orientation was found, $58 \%$ expressed this opinion. The prevalence of volunteering, similarly, evidences the intrinsic value of work (Wilson \& Musick 1997; Strauß 2009).

Jon Elster proposes a theoretic approach to the work-leisure dilemma that provides a cue to such evidence of widespread normative employment commitment. Inspired by the Marxist tradition, he sees work as a potential source of self-realisation. ${ }^{12}$ "Work, according to Marx, is rewarding and painful; moreover it could not be rewarding without being painful" (Elster 1986: 110). The potential of work to foster self-esteem largely stems from the associated recognition granted by others (ibid.: 106). This social acknowledgment is manifest in the wage that work generates, but also - as Weber (2005 [1922]) was probably the first to point out - in the social status enjoyed by certain occupations.

Mastering a task enhances self-efficacy. Hence, work can be pursued as a source of happiness, though in a different way than leisure or consumption. Specifically, the satisfaction from doing a job well is gained in the form of a deferred gratification after the accomplishment of the task. This deferment is one reason why people would - in an often myopic manner - prefer not to work. The choice between work and leisure resembles an "intrapersonal, intertemporal Prisoner's Dilemma [...], because the person neglects the positive externalities of work" (Elster 1986: 111). Myopia and risk aversion can be insurmountable obstacles to engaging in work, even though being productive would eventually improve personal well-being in the long run.

The central implication of this argument is that people can have an interest in work, over and above the earnings that it generates. In consequence, a worker's preferred retirement age will not only depend on the balance between his or her wage and pension entitlements but also on his or her work orientation.

According to Elster's account, adopted here, the necessary condition for an emphatic work orientation is that the job task is appropriate to the worker in terms of difficulty and amount of strain. Ideally, it should be interesting and challenging but not overly demanding or even physically damaging. Albeit

12 In this view, work is only one of the activities which lend themselves to self-realisation. Elster divides human activities into the categories of consumption (e.g. eating, reading a book), self-realisation (e.g. playing chess, building a house, acting, writing a book), spontaneous interpersonal relations (e.g. meeting friends, making love), and drudgery (e.g. cleaning the streets, working in assembly line) (Elster 1986: 99). 
often helpful, wages are not a necessary condition for work to be gratifying, as demonstrated by empirical evidence concerning the positive influence of volunteering on well-being (Thoits \& Hewitt 2001). Instead, work orientations are contingent on individual work experience. This line of reasoning is largely supported by evidence on differential perceptions of work (Siegrist et al. 2006; Svallfors 2006: 38 f.). The conclusion that follows is that the taste for early or late exit from work is also likely to depend on the skill requirements of one's job and as well as on actual working conditions. As a consequence, retirement preferences are expected to vary critically across occupational social class.

\subsubsection{Age Norms and the Life Course}

While work orientations are largely entrenched in one's own work experience, age norms are created within a social environment. Other than labour-supply decisions in mid-adulthood, retirement is a genuine biographical milestone loaded with social significance. Despite being reversible in principle, for the great majority of people, retirement de facto puts a permanent end to working life. ${ }^{13}$ Moreover, it is characterised by major uncertainty with regard to the concomitant features of post-working life. Uncertainty adds complexity to cost-benefit calculations and makes actors sensitive to significant signals that allow for a more precise estimation of the "value" of retirement. Therefore, standardised life course patterns can serve as blueprints for appropriate decision-making in key life transitions. Lacking reliable information about the expected outcomes of earlier vs. later retirement respectively, actors take note of the examples set by others in their social environment. In this way, people's attitudes towards retirement are shaped by the temporal norms of the institutionalised life course.

Following life course theory, we expect individual retirement behaviour to be under the influence of age norms that define a particular age (range) as appropriate for the transition from work to retirement. In Coleman's terminology (1990), age norms can be prescriptive or proscriptive social norms. A prescriptive age norm dictates an age when one should retire. A proscriptive age norm stipulates that one should not retire before or after a certain age. These temporal scripts for retirement entail both duties and entitlements. On the one hand, age norms of retirement amount to the social obligation to work until reaching a

13 Returning to work after having retired from the labour market, or "unretirement," is still a marginal phenomenon in continental Europe, albeit more common in the Anglo-Saxon world. 
given age threshold. On the other hand, age norms also legitimise the eventual end of the working career (Kohli 1987). ${ }^{14}$

It should be noted that the age-norm hypothesis does not imply uniformity across all social strata. Instead, the normative blueprints for retirement will, to some extent, vary according to the target actor's situation (gender, job, family situation, etc.). In Cristina Bicchieri's words, age norms are local, "insofar as their content and recommendations are context-dependent" (Bicchieri 2006: 80). People's normative beliefs about the appropriate retirement age for a construction worker can obviously differ from their beliefs regarding, for instance, a judge's retirement. Nevertheless, it must be possible to define a common core of these beliefs to qualify as social norms. And only if there is some general consent on retirement behaviour in a society as a whole can we really speak of age cultures (see section 3.1.5).

Within the conceptual framework outlined here, the term age norms is simply a short-cut for age-related social norms (section 2.4). Social norms are defined as subjectively acknowledged obligations or interdictions of actions that are shared by most members of society, or by the majority of a specific social group. According to Elster (1989), social norms are essentially non-consequential, that is, not outcome oriented. In other words, social norms are not a means to an end but an end in themselves; actors adopt social norms as goals in their own right. Often, the violation of social norms will trigger sanctions, for example, in the form of symbolic depreciation by others and a consequential loss of social prestige. But external sanctions are not a necessary condition for the existence of an age norm (Bicchieri 2006: 24). ${ }^{15}$ "Social norms have a grip on the mind that is due to the strong emotions their violations can trigger" (Elster 1989: 100). ${ }^{16}$ If a social norm is internalised to a high extent, the potential loss in self-respect can be sufficient to induce norm compliance (March 1994: 65).

The emphasis placed here on internalised social norms that are endorsed by most members of a society goes hand in hand with a conceptualisation of

14 The age norms theorem does not necessary imply that people act according to an overarching life plan or holistic biographical design, as suggested by the concept of "life course agency" (Hitlin \& Elder 2007).

15 This conception diverges from rational-choice theory and some sociological approaches, which define social norms as mere constraints on self-interested action (Coleman 1990; cf. Hechter \& Opp 2001b). Notably, the social-norms-as-constraints view has particular difficulties in explaining the emergence of social norms as well as norm compliance (Elster 1989; Anderson 2000).

16 Some rational-choice scholars have recognised that norms can be internalised (Coleman 1990: chap. 11). Internalisation means that the individual builds up an internal sanctioning system. However, although shame and guilt may resemble internal sanctions, this terminology conceals the societal origin of normative values. 
age norms that form part of most actors' preferences. Bicchieri's theory of social norms offers a conceptual clue here (Bicchieri 2006: chap. 1). According to her account, social norms are erected on the basis of actors' conditional preferences for complying with a given rule. Accordingly, ego will prefer to conform to the rule if he or she believes that a sufficiently large subset of a target population complies with the norm (empirical expectation) and expects ego to obey as well (normative expectations) (Bicchieri 2006: 11-31). ${ }^{17}$ In this way, conformity is motivated by "the recognized legitimacy of mutual normative expectations" (ibid.: 25).

\subsubsection{Social Class, Gender and Choice: The Scope of Social Stratification}

The high incidence of involuntary retirement (see section 2.3) casts serious doubt on the micro-economic modelling of transitions to post-work life as a free decision. In fact, in a situation in which the "feasible set" (Elster) of possible actions is very small, rational-choice theory can contribute little to the explanation of social behaviour. For instance, it is not very meaningful to calculate the option value of continued work (see section 2.2) for someone who suffers from a severe disability. The less choice exists, the more potent are theoretical accounts that refer to structural constraints for the explication of an action. It should be noted that the term "constraints" is used here in the sense of "hard constraints" rather than "soft constraints." While the former constrain individual decisions "by making some options absolutely unfeasible" (Elster 2004: 188), soft constraints do so only in relative terms by affecting the costbenefit trade-off between competing goals. That is, constraints shall refer to the lack of choice rather than to the economic costs related to alternative choices. The latter shall be subsumed under the term "incentives" here. The key criterion for hard constraints in retirement is having the chance to be employed.

Inequality of opportunities is implicit already in the classical notion of social structure (Smelser 1988: 105). Accordingly, individual actors are restricted in their range of possible actions depending on their position within social relationships that grant access to economic resources (Giddens 1997).

$\mathbf{1 7}$ To be accurate, Bicchieri acknowledges (in condition 2b) that for some individuals, avoiding punishment is the main reason for compliance. However, "[t]he common observation that norms transgression is often accompanied by punishment (or the expectation of punishment) does not entail that norms are only supported by sanctions, in the sense that if sanctions were not there, conformity would be entirely absent. [...] It is important to acknowledge that different individuals may need different normative expectations in order to be prepared to obey a norm, and that an individual may follow some norms, but not others, in the absence of any expected sanction" (Bicchieri 2006: 24). 
DiPrete (2002) has argued that the structure of social stratification is revealed most critically in the conditions experienced in risky life events. The varying scope for individual decision-making should thus be a crucial dimension in retirement as well. Concretely, the opportunity structure in retirement is dictated by the accessibility of the various pathways that lead from work into retirement (cf. section 3.3.1).

In the following, I discuss the theoretical importance of class and gender with respect to retirement behavior. According to the vast literature on social class, life chances are generally closely connected to class membership (Mayer \& Carroll 1987; Erikson \& Goldthorpe 1992; Wright 1997; Sørensen 2000; Grusky 2001a). Following a class-analytic account (cf. section 3.3.2), market position determines the individual endowment of material resources, which in turn determines life course mobility. For example, access to early retirement benefits varies according to occupations, as social-security regimes are often fragmented across professional divisions. In this sense, occupational pensions are rents (Sørensen 2000) par excellence. Vice versa, the risk of being forced into early exit from work depends on the nature of the employment relationship. This is particularly true for the risk of ill-health and disability, which hugely depend on job characteristics. The strong class effects on health and mortality are well documented (Feinstein 1993; Marmot et al. 1997; Davey Smith et al. 1998; Rose \& Pevalin 2000; Hoffmann 2008; Layte \& Whelan 2009). Similarly, the likelihood of becoming unemployed varies strongly according to social class, because individuals' skill levels and degree of employment protection are also closely related to their position within the occupational hierarchy (Gallie et al. 1998: chap. 5; Layte et al. 2000). In sum, it should be expected that the ability to withdraw from work and take up an old-age pension under favourable conditions is highly class-selective (cf. sections 3.1.5).

The gender divide is another crucial dimension of social inequality. Yet, the precise analytical location of the gender category in stratification theory has been the subject of a long debate (Sørensen 1994). Much of this dispute has been carried out in the form of '"class first' versus 'patriarchy first' arguments" (Crompton 1989: 569). Feminist scholars have criticised that an occupational definition of social class neglects the fundamental sexbased division of labour (cf. Heath \& Britten 1984; Stanworth 1984; Sørensen 1994). Accordingly, the exclusive focus on the allocation of persons to jobs precludes an understanding of sex-based inequalities in modern societies. Apart from ignoring women's home production, the standard class-analytic approaches would also not be able to take account of the evident gender segregation on labour markets, in which women systematically occupy jobs with inferior status and career prospects. Against these assertions, the conventional approach maintains that it is the position of one's job in the hierarchy that determines the socio-economic status of the incumbent and 
not his or her sex (Goldthorpe 1983). In other words, gender is not recognised as a central organising principle of economic resources in society in the order of occupations. The status implications of sex are not denied altogether but are rather assumed subordinate to the rank order of occupational strata (Lockwood 1986: 21).

What seems crucial to take away from Feminist and gender-theoretical contributions to stratification theory is the relevance of sex-based labour market segregation and gender discrimination. To the extent that job-related opportunity structures are gender-specific, the patterns of decision-making in retirement will also be gender-specific. Women continue to be employed in a narrower range of jobs than men (Gundert \& Mayer 2012). Specifically, they are more likely to be employed in clerical, sales, and service positions, particularly in the public sector (Dunn \& Skaggs 1999). Moreover, within given career paths, the "glass ceiling" effect impedes women from being promoted to top positions (Goldin 1990; Blau et al. 1998). At the same time, there is solid empirical evidence that women still receive less pay for equal work, a phenomenon known as the "gender wage gap" (OECD 2002a: chap. 2; Aisenbrey \& Brückner 2008).

These different forms of the unequal job situations of men and women should be taken into consideration in the study of men's and women's retirement behaviour. The way in which the regularities governing women's retirement behaviour differ from those validly identified for men is not well understood thus far (Hurd 1990: 589 f.; Kim 2009: 525; Jefferson 2010: 116). Correspondingly, a pending task addressed by this study is to evaluate whether gendered labour market structures have an impact on women's work-exit behaviour independent of social class.

Beyond the question of inequality of opportunities, a recent debate has evolved around the impact of gendered preferences on subsequent labour market outcomes. Spurred by Hakim's provocative "preference theory" (Hakim 1996, 2007), the alleged influence of gendered preferences has become subject to a heated controversy (Hakim 2003; McRae 2003a, b). Hakim not only argues that women's work orientations depart from men's in fundamental ways but also claims that differences in the employment participation of women can be causally attributed primarily to their work-family preferences. ${ }^{18}$ Not surprisingly, sociologists have voiced strong criticism against this view, maintaining that social structures and institutions impose serious constraints on work-family decisions (McRae 2003a, b; Duncan 2005; Crompton \& Lyonette 2006; Stähli

18 There has been also a recent attempt to apply the model to leisure activities in old age (Vidivicova 2005). 
et al. 2009). The principal objection is that preference theory fails to appreciate the far-reaching scope of the restrictions upon women's set of feasible actions. ${ }^{19}$ The debate seems to have settled on a viewpoint that sees labour market outcomes as the product of a confluence of institutions and preferences (Kan 2007; Kangas \& Rostgaard 2007; Debacker 2008; Stähli et al. 2009).

In my opinion, the conceptual clues from this strand of literature can also be made useful for retirement research. Distinguishing the impact of choice from the impact of constraints on retirement transitions is crucial for uncovering the social mechanisms at work for different groups of actors. Although seldom spelled out explicitly, the notion that gender has a two-sided influence on retirement behaviour is not alien to life course theory. In fact, the assumption that career trajectories as well as family-related transitions shape later actions via mechanisms related to both agency and structure is implicit in many life course studies. Class and gender theory help extract meaningful, testable hypotheses from this fundamental insight.

Beyond class and gender, research in social stratification has increasingly looked at ethnicity as a "new" axis of inequality (cf. Esping-Andersen 1993a). For our purposes, the issue at stake here is the extent to which ethnic differences or racist discrimination within the labour market have an impact on retirement patterns. In this vein, scholars have compared the forms of work exit of AfricanAmerican and white men in the U.S. (Burr et al. 1996; Hayward et al. 1996). More recently attention has also been paid to the retirement behaviour of the Hispanic population (Flippen \& Tienda 2000; Flippen 2005; Brown \& Warner 2008). ${ }^{20}$ In most of European retirement research, by contrast, race and ethnicity have hardly been addressed thus far. The main reason for this is that the share of non-nationals among the retirees in most Western European countries is still marginal. Correspondingly, ethnic inequality will not play a role in the remainder of this study. Yet, this axis of inequality will gain importance in the near future as the generation of post-war immigrants approaches retirement age.

To sum up, social class and gender are regarded as the most pertinent theoretical categories of social stratification that need to be analysed in order to understand the unequal distribution of retirement opportunities in contemporary Western Europe. I expect that class and gender influence

19 "[U]nderpinning the data [...] are social structural/class differences in subjective rationality - in women's interpretations of the courses of action open to them relative to their goals - which produce both differences in labour force participation after childbirth and ideologies about motherhood and families" (McRae 2003a: 330).

20 Notably, measuring the influence of ethnic origin on economic outcomes is complicated by strong labour-market-selection effects and data availability Critical problems with studying migrants' retirement are caused by return migration and limited data availability. (for an overview of the situation in Germany cf. Mika 2006) 
retirement timing strongly, because differences in employment chances and health are stratified according to both dimensions. Despite the acknowledged influence of divergent labour-shedding strategies, firm-level mechanisms are not scrutinised in detail but controlled through the kind of industry in which an individual is employed.

It should be kept in mind that, as argued above, work orientations and age norms are likely to be structured along the very same axes of social stratification as are structural constraints. In order to advance our understanding of work-exit dynamics, it is therefore crucial to disentangle the decision element from the opportunity structure correlate of social class and gender respectively. The latter comprises everything connected with social class or gender that shapes the feasible set of options available to an individual approaching the end of working life. Conversely, the former refers to the class and gender gradient in workleisure (or work-family) decisions made by elderly workers, i.e. the retirement choices that are made by actors given the constraints they face.

\subsubsection{Linked Lives and Family Effects}

As already mentioned in section 2.4, the mutual dependence of spouses' retirement decisions has been subject to a lively debate (Allmendinger 1994; Gather 1996; Drobniĉ 2002; Kim \& Moen 2002; Szinovacz \& Davey 2004). On a more general level, the impact of the family domain on individual labour market trajectories has also been demonstrated by the literature on coupled careers (Blossfeld \& Drobnic 2001). The theoretical framework presented here embraces the principle of "linked lives" (Elder 1995), which, as advanced in section 2.4, assumes an influence of family issues on retirement planning.

Family circumstances are expected to reshape individual situational preferences in function of the vigorous social norms. In the main, we can distinguish three different ways in which family influences retirement decisions: (1) the "joint lunches" effect; (2) care work; (3) household finances.

Ad (1): The "joint lunches" effect refers to a preference for synchronised retirement within the couple. The synchronisation of his-and-her retirement can be driven by mutual expectations between spouses regarding time use. In particular, both partners may share the preference for joint retirement and consequently attempt to synchronise labour market withdrawal.

However, joint retirement may also be strongly preferred by only one partner, while the other prefers an asynchronous timing of retirement. For example, it has been shown that men carry a higher risk of suffering from symptoms of depression when their wives retire later than themselves (Kim \& Moen 2002; Szinovacz \& Davey 2004). To the extent that husbands anticipate these adverse consequences, it is plausible that they either postpone their 
own retirement or urge their (often younger) wives to retire as well. In fact, the employment situation of husbands has been found to exert a larger effect on their wives' retirement decision than vice versa (Drobniĉ 2002). Spouses who disagree about retirement planning are likely to negotiate the timing of their respective labour-force withdrawal by evoking partnership roles and norms of aging.

Ad (2): A different "linked lives" constellation emerges when a parent becomes dependent on permanent care, and one of their children (in law) stays home to care for them. The degree of voluntariness can differ in these situations. Depending on the national system of long-term care and family liabilities, purchasing professional help on the market may be not be affordable for everyone (Esping-Andersen 1999: chap. 4). However, adult children may also freely decide to take care of their parents on the basis of a moral sentiment of duty, despite having sufficient resources to pay for nursing services. Furthermore, norms related to gender or birth order may be evoked among siblings or spouses to assign caring responsibilities. In this context, some authors have pointed to caring obligations as a markedly sex-specific motivation for retirement (Kim \& Moen 2002; Jefferson 2010). Gender-graded norms arguably play an important role here (Haberkern 2009: chap. 8), which is why particularly daughters and daughters-in-law are expected to undertake caring duties.

Ad (3): Preferences aside, family events can also have an immediate impact on household finances. On a very general level, the low employment rate of women in many countries has been attributed inter alia to a system of taxation that stabilises the male-breadwinner model (Orloff 1993: 316). Accordingly, a traditional gender division of labour is promoted by a fiscal system that imposes lower marginal tax rates on single-earner couples, or "unequal one-and-a-half patterns" (Pascall \& Lewis 2004: 387). This social policy argument explains gender differences in retirement timing by reference to taxation rules at the country level.

Another way in which household processes modify economic retirement incentives is through changes in marital status, particularly through divorce from or death of the spouse. Since widowhood often causes a loss of income, it may increase work incentives for the surviving spouse. In this case, widowhood would induce later retirement. However, the effect can also work the other way around: in Germany, for example, the receipt of a survivor pension is, to some degree, incompatible with earnings (cf. chapter 7). Since continued work here means to forego part of one's potential income, we would rather expect widows and widowers to leave the labour market prematurely. Any adverse health effects following the death of a spouse would presumably lead to early retirement, too.

Divorce, too, can have a variety of effects on the financial situation of individuals approaching retirement. Depending on circumstances and legislation, it is possible that divorced persons increase or decrease their labour supply after divorce (cf. Chiappori et al. 2002). If pension-sharing regulations 
are in place, divorce also alters individual pension entitlements, which, in this case, are redistributed in favour of the (ex) spouse with the lower income. A competing hypothesis is that due to adverse health effects divorce leads to earlier exit from work.

The previous retirement literature has paid far more attention to the "joint lunches" effect than to the other two kinds of household-level interactions mentioned. Today, caring obligations still only affect the work-exit decisions of a limited number of workers, but due to population aging, caring work will be of increasing importance for retirement behavior in the future. The third factor mentioned here, family finances, has hardly been explored in the existing literature at all. In particular, there is limited knowledge of the relationship between divorce or widowhood and retirement. This mechanism is potentially sizeable in its effects on a given worker but is again confined to a relatively small group of individuals.

In sum, the "linked lives" theorem captures a peculiar set of interdependent retirement decisions and family effects. The related aspect of asymmetric power relations and family bargaining will not be pursued further in the following analyses. Instead, the influence of the household situation on retirement behaviour is captured via actors' family-related retirement preferences (see next section) and financial considerations.

\subsubsection{Synthesis: Constraints and Preferences in Retirement Behaviour}

In the foregoing sections, a set of concepts from life course and stratification literature have been adopted as theoretical devices for the study of differential retirement behaviour. Drawing on the contributions to social theory by Jon Elster and Christina Bicchieri, this synthesis intends to expound how these various theoretical arguments can be integrated into one coherent approach.

Essentially, outcomes in terms of retirement timing are expected to differ according to opportunity structures and preferences. Actors are considered receptive to monetary incentives. Specifically, they are expected to conduct rational cost-benefit calculations whenever they dispose of at least some "room for maneuver." However, treating all unemployed older workers as helplessly determined to retire wrongly asserts the all-importance of structural constraints. Push approaches are often short of falling prey to a "structuralist fallacy," whereas pull approaches frequently adopt a flawed voluntarism in neglecting the narrowness of the opportunity set available to actors. How much choice actually exists for older workers is an empirical question that depends on the worker's employability as well as on the design of social policies. 
In short, the transition from work to retirement is modelled in this study as the result of individual decisions within structural constraints. Yet it is inappropriate to make a clear-cut distinction between voluntary and involuntary retirement. Most people approaching retirement can be expected to dispose of some discretion for the timing of their retirement. Instead of assuming a dualism between deliberate and imposed retirement, we shall rather distinguish varying degrees of individual control over the status passage from work to retirement. This line of argument is analogous to Sen's (1985) concept of "agency freedom." In an individual's transition into retirement, the "set of functioning vectors within his or her reach" (Sen 1985: 200-204) is given in form of the accessibility of different pathways into retirement. Whereas the welfare state is the main gate-keeper of early exit pathways, the accessibility of late-exit pathways is preponderantly controlled by employers.

At the end of working life, people do not differ only with respect to their opportunity structure but also with respect to their retirement preferences. Two sources of retirement preferences will be considered: work orientations and age norms. Sections 3.1.1 and 3.1.2 have shown on theoretical grounds why individuals are likely to differ with respect to work orientations per se, but also with respect to local age norms of retirement, which have their origin in the institutionalised life course. Since there are competing understandings of social norms and preferences in the social sciences (cf. Hechter \& Opp 2001a; Bicchieri 2006), some additional clarification about terminology is useful here.

In this study, I will rely on the theoretical concepts of work orientations, social norms, and preferences. Figure 3.1 provides a conceptual map that shall help illustrate the relationship between these concepts. Work orientations have been characterised in section 3.1.1 as the genuine value ascribed to working in one's job vis-á-vis being inactive, independent of the wage it generates. Work orientations are part of ego's preferences. In turn, social norms are defined in section 3.1.2 as non-consequential beliefs that prescribe or interdict particular actions and that are shared among the majority of individuals within a social group. If a symmetric social norm is internalised, it is treated as an element of the actors set of preferences as well. ${ }^{21}$

The contrast between symmetric (self-regarding) and asymmetric (otherregarding) norms is important. Many social norms are shared by most members of a particular group, but not by all. For the minority, these norms are external. Rather than part of their preferences, they represent a constraint. Vice versa, ego may hold asymmetric norms that concern the actions of others. But by definition,

21 This conception departs from rational-choice theory in that social norms are understood as a sub-set of preferences rather than self-imposed constraints to a somewhat ambiguous primary orientation. 


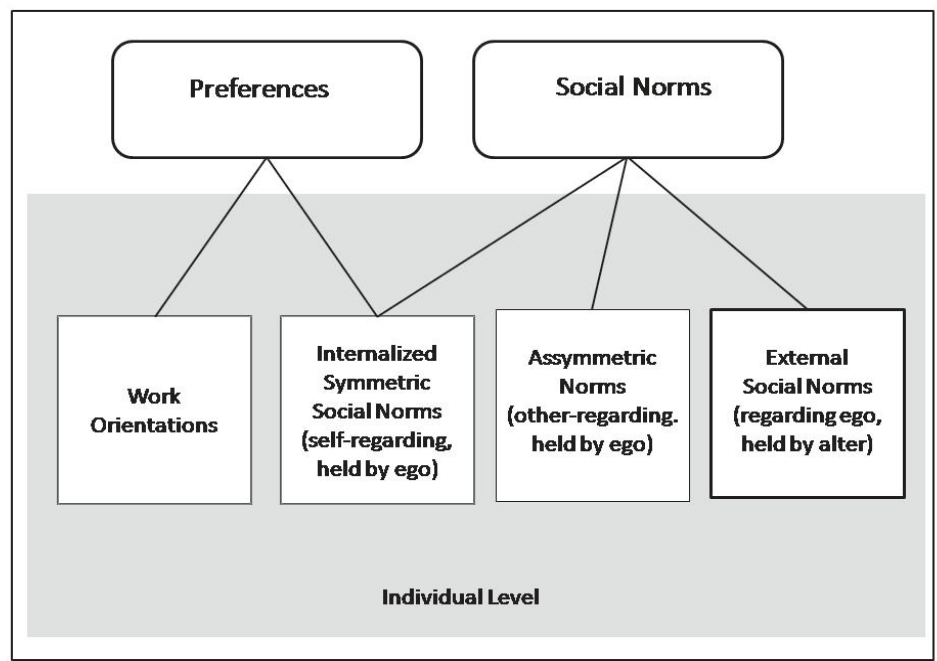

Source: own elaboration.

Fig. 3.1 Conceptual Map of Preferences and Social Norms.

the majority of target actors of a norm also subscribe to it. Correspondingly, the focus in this study is mostly on age norms as internalised symmetric norms.

Retirement preferences are thus mainly composed of work orientations and internalised age norms. While the former are goal-oriented, because work is pursued as a means to self-realisation or social status, social norms are pursued as goals in themselves.

With these definitions in mind, figure 3.2 illustrates the analytic account of choice within constraints in retirement that is adopted for this study. Generally, the actor's retirement decision is constrained to varying degrees by economic circumstances, giving rise to a particular opportunity structure: while employability is crucial to one's chances of staying on the job, pension rights grant differential opportunities for early exit. Within these limits, workers supposedly carry out rational cost-benefit considerations in a similar way as stipulated by labour-supply theory. Generous early retirement arrangements represent an incentive to withdraw from work, while foregone income imposes implicit costs on early exit.

Work orientations also enter into rational cost-benefit calculations, which determine ego's self-interest in a given situation. The more emphatic ego's work orientation, the higher the utility ascribed to the option of continued work. It is thus through instrumental cost-benefit calculations that work orientations exert an influence on retirement behavior. If an actor does not subscribe to the norms that are operative for the social groups of which he or she forms a part, these 


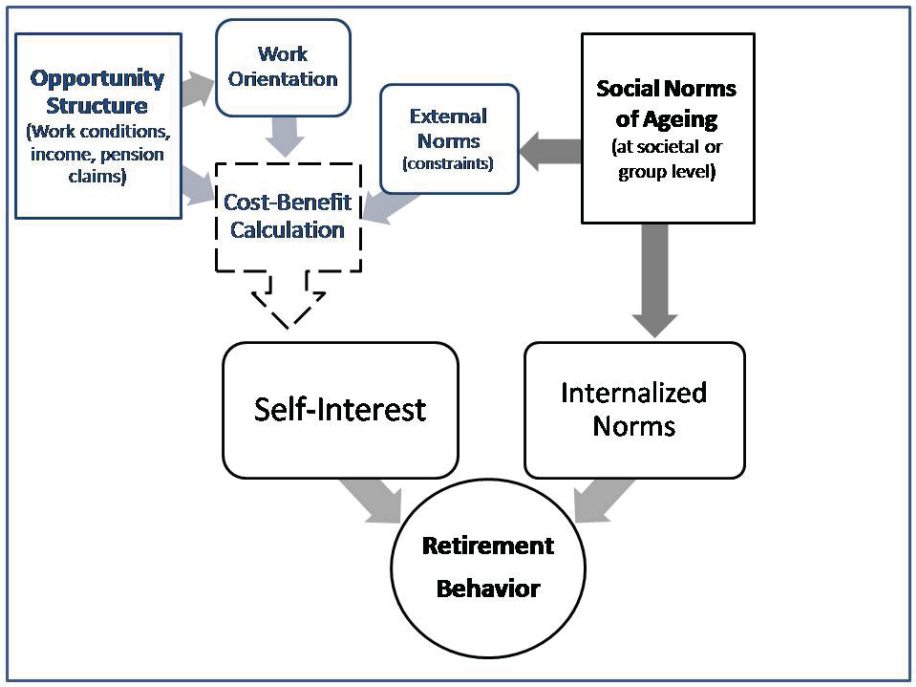

Source: own elaboration.

Fig. 3.2 Individual Agency Within Constraints in Retirement.

norms can suppose additional costs, in so far as there are sanctions for norm violation (e.g. ageist discrimination at the workplace).

Finally, ego decides about his or her retirement timing in accordance with his or her self-interest and internalised social norms. In case of conflict between these two incommensurate dimensions, ego involves in self-negotiations as to which side should have priority. The more imperative structural constraints are the less the result of cost-benefit calculations is influenced by work orientations or social norms.

An additional intervening factor may be the family domain. On the one hand, the importance given to time spent with family exerts a direct (negative) influence on the intrinsic value of work. A person's work-orientation can be broken down into the relative satisfaction gained from work and family/leisure activities respectively. Moreover, the linked-lives tenet makes reference to preferences being shaped by interdependent processes in the household (cf. previous section). On the other hand, family obligations can also enter retirement decisions in the form of external or internalised social norms. For instance, women living in a traditional family arrangement may feel morally obliged to stay at home to care for a frail parent (internalised norm) or may be pressured to retire by their dominant husbands who, driven by traditional gender roles, do not tolerate their wives being active when they are already retired (external norms).

Critically, particular internalised norms and work orientations are distinct at the analytical level but will be often be largely indistinguishable in empirical 
research. For instance, gender norms and age norms may be blended together. The co-existence or fusion of different (and sometimes conflicting) motivations is a characteristic feature of human agency. If various motivations are in conflict, the priorities given to the respective dimensions differ across individuals. In most cases the analyst will be unable to identify the precise mix of reasons for an actor's attitude towards retirement. It is normally too much to ask survey respondents (or even interviewees in qualitative research) to place themselves in counter-factual situations to rigorously distinguish self-interested costbenefit calculations from social norms. Nevertheless the analytical distinction is seen as crucial for our theoretical understanding of retirement behavior.

Closely related to social norms is "culture," of which I will speak when referring to normative orientations at the societal level. Different sets of agegraded norms found at the level of nation states will be referred to as age cultures (cf. De Vroom 2004). Where appropriate, I will refer to "attitudes" as the empirically observable manifestations of norms and preferences, but this term does not carry distinct theoretical meaning.

To sum up, I consider the following as principal sources of social variability in retirement timing: retirement opportunities, work orientations, and age norms. Firstly, the opportunity set available to workers facing retirement is socially stratified. The employment chances of some workers are seriously constrained because of unemployment or disability. These late-career risks can be expected to be very unevenly distributed across occupational groups. Attractive early retirement programmes are similarly restricted to certain collectives of workers. The emphasis on social class intends to capture the way in which occupational boundaries render retirement opportunities unequal. Gender differences are hugely important for late-career constraints as well, be it because of sex-based labour-market segregation, the "motherhood penalty" inherent in pension legislation, or human capital deficits stemming from employment interruptions.

Secondly, the intrinsic value related to work is contingent upon job characteristics. Insofar that classes differ fundamentally with respect to working conditions and the possibilities to find self-realisation in work, they are as well expected to differ with respect to their work orientations. The social prestige or status of a job plays a role here as well. With respect to gender, it has been argued above that women and men are likely to act differently given the same opportunity structure because their work orientations may diverge systematically. For instance, care responsibilities as well as coupled retirement decisions may affect men and women differently.

Thirdly, age-related social norms can be expected to diverge between occupational and gender groups. Some occupational groups receive privileged treatment in the system of social welfare, which often entitles them to an anticipated old-age pension. Age norms are therefore expected to vary according 
to membership in occupational groups with similar social standing and career trajectories. As outlined above, these similarities are synthesised in the concept of social class (see section 3.3 .2 below). Similarly, many pension systems establish different retirement-age thresholds for men and women. Under such conditions it is highly plausible that gender-specific views emerge concerning the appropriate age for retirement and then become post-hoc established as age norms.

In the empirical chapters of this study, I shall strive to examine how class and gender effects, stemming from unequal opportunities and divergent preferences respectively, shape the timing of retirement in contemporary European societies. Following such an approach, I maintain, also has the potential to contribute both theoretically and empirically to a better understanding of the controversial relationship between class and gender.

\subsection{Institutions and the Life Course: Establishing the Macro-Micro Linkage}

The timing of retirement is dependent on manifold country-specific conditions. Three kinds of macro-to-micro chains need to be taken into account here: firstly, social policies, and especially pension systems, are of critical importance, as they decide the availability and financial attractiveness of exit pathways. Secondly, the configuration of the labour market and the structures of occupational segregation determine the employability of different classes of elderly workers, and hence, the opportunity structure that individuals face in the transition to retirement. Thirdly, age cultures, in the sense of country-specific bundles of agegraded social norms (see previous section), are expected to cause cross-national differences in the age of retirement.

Therefore, this study not only addresses the mechanisms of differential retirement behaviour on the micro level but also the impact of formal and informal socio-economic institutions on the macro level. In doing so, it aims to contribute to our understanding of the "institution-life course outcome linkage" (Mayer 2001: 101) in retirement. The impact of the three mentioned dimensions - pension systems, labour market structures, and age cultures - on individual retirement behaviour will be captured by applying a comparative research design (cf. Mayer 1997; Heinz 2001).

This section outlines the macro-sociological concepts that shall help to identify contextual effects on retirement behaviour. I will first lay out the methodological approach that is connected with the use of the welfare regime typology in this study. Subsequently, I attempt to transcend the limits between individual- and country-level explanations by introducing a set of macro-micro interactions that may interfere in work-exit processes. 


\subsubsection{Welfare Regimes Revisited}

The welfare regime approach, which has been discussed at length in section 2.5, is adopted here to address cross-national variation in push and pull factors. Welfare regimes are useful, short-hand descriptions of institutional configurations, which cover social policies as well as labour market regulation. Presenting regime characteristics as stylised facts, they can function as complexity-reducing prisms that highlight pertinent country differences. If interpreted as a set of ideal types, in the strict sense of a "heuristic theoretical device to facilitate the measurement of reality and the comparison of empirical forms" (Grint 2005: 103), the welfare-regime typology represents a formidable analytic tool for the comparative study of retirement.

Specifically, a four-fold typology, which, along with the three original regime types, includes the fragmented welfare regime, will be used in the remainder of this study. Despite legitimate criticisms regarding the classification of particular countries, there is a fundamental trade-off between accuracy and parsimony, which makes each further refinement of typologies costly in terms of a loss of analytical potential. Building on a welfare-regime approach has the added advantage of making a considerable body of research accessible for comparison. Institutional arrangements are well-documented in the literature, often by using the welfare typology as a blueprint.

In any event, welfare regimes alone are not sufficient as an analytical reference at the macro level; instead, national context needs to be conserved in the comparative analysis of individual-level outcomes. The empirical clustering of countries could turn out to be very different from the predictions that follow from the regime approach. By simply replacing country names with the best-fitting welfare-regime label, the analyst could easily fail to notice relevant differences within the pre-defined country clusters. Moreover, using the regime approach always runs the risk of creating black-boxes. Since regimes are defined on the basis of a large array of shared characteristics, it is not easy to know which institutional features precisely are responsible for the empirical similarities between certain families of countries. Hence the importance of replacing country and regime names with substantial macro-level indicators. As far as possible, the international variation in retirement patterns should be explained in terms of concrete institutional and structural differences between societies. In short, the regime typology can supplement, but not substitute, a disaggregated country-level analysis (Mayer 2001).

Another caveat to using the regime approach shall be avoided: EspingAndersen's typology is formulated on the basis of both institutional characteristics and the associated patterns of work and social stratification. Critically, this implies that using the approach to explain employment issues is 
always close to a tautological form of reasoning (Arts \& Gelissen 2002). For the sake of methodological rigour, it is therefore necessary to de-couple individuallevel outcomes of social-policy intervention from the defining features of welfare regimes. In order to be applicable to social differences in retirement timing, the regime classification has to be deprived a priori of the supposed country patterns of retirement timing and social stratification. Rather, the latter will have the status of hypotheses, which will be spelled out in detail and subsequently tested in the respective empirical chapters.

As for the third corner of the welfare triangle (state-market-family), regimespecific family dynamics are likewise submitted to empirical testing instead of simply being defined as concomitant features of certain welfare regimes. Specifically, gender differences and household-level processes are addressed at the micro level (see sections 3.1.3-3.1.5), as well as in relation to various macromicro interactions (see the following section).

\subsubsection{Macro-Micro Interactions}

Institutional and structural features of national societies do not only influence the extent of early retirement practices in a country. They may also modify the very interplay of social mechanisms that determine retirement behaviour at the individual level:

"For given life course transitions there are not only fairly complex explanatory stories to tell on the level of individuals, households and families, but partly additional explanatory stories on the level of local and national communities. [...] To provide an adequate account on cross-national variations forces one to specify causal models not only on both levels, but also on the detailed interchanges between both levels" (Mayer 1997: 209).

Although implicit in parts of Esping-Andersen's writings on the welfare state, the multi-level nature of many of the involved processes is not systematically spelled out in his work, nor, for that matter, in the work of most other scholars researching retirement in a comparative fashion. However, given the institutional embeddedness of individual labour market transitions (cf. section 3.1.5), taking account of interactions between macro and micro variables appears crucial for understanding retirement behaviour. In the present study, I shall pay special attention to the interrelations that cut across the boundaries of the micro-macro dualism. Four different mechanisms that mediate between the macro and the micro level shall be distinguished: 


\section{Institutional Filters}

Welfare institutions do not merely affect the average retirement age in a country; at the same time, they also potentially alter the socio-economic factors related to early or late exit from work. For instance, employment-protection legislation may affect class inequalities in retirement opportunities by increasing the costs for employers of shedding elderly employees, and, in this way, reduce the risk of unemployment for older, low-skilled workers.

Moreover, most pension systems contain multiple parameters that modify the incentives for early retirement for different social groups. For example, a guaranteed minimum pension makes early retirement more attractive for lowwage earners. Moreover, in a country where early pension entrance is granted to women but not to men, the pattern of gender stratification in retirement is likely to be different than in a country that does not apply different pension rules to men and women. Likewise, if early retirement privileges are restricted to certain occupational groups, this feature of pension system design is expected to produce a distinctive class pattern in terms of labour-force withdrawal.

Institutional filters are the most commonly considered macro-to-micro chain (cf. Buchholz et al. 2006; Ebbinghaus 2006a). To the extent that welfare-state intervention influences the individual-level determinants of retirement timing, we will observe corresponding country- or regime-specific patterns of social diversity that depart from (or even transcend) the generic model of class or gender stratification.

\section{Selection Effects}

In studying only a specific subgroup of the population - i.e., older workers who remain alive and economically active until age 50, when they enter the "risk" to retire (see the section 3.3.1 for a detailed discussion of the adopted-retirement concept) - there is always a risk of confounding the outcome of interest with a selection process. As Berk puts it, "whenever one has a nonrandom sample, the potential of sample selection bias exists" (Berk 1983: 391). This may occur because some (typically unobserved) factors lead a certain type of individuals to self-select into the subset of the population in which our study is interested. The smaller the group in question, the stronger the potential selection effect. The selectivity of the target population is intentional, as it is inherent in the conventional definition of retirement; but the implications of this selectivity should nevertheless be taken into consideration in empirical analyses.

When applying this rationale to the comparison of work-exit processes between countries, it is possible that the sheer aggregate size of a particular social group changes the micro-level factors associated with retirement 
behavior. A prime example is the way in which female inactivity affects women's retirement ages. When only a minority of women stay in the labour market long enough to retire, it is probable that this group is not representative of all women of their age. Accordingly, a hypothesis that we will test in chapter 5 claims that the fewer women work, the more women's retirement will resemble men's retirement behaviour. If this holds true, the effect of being female on retirement ages would be dependent on the female employment rate in the country.

Correspondingly, the relative size of a particular class may be directly related to the average behaviour among the members of this class. For instance, in his analysis of the educational field in France, Pierre Bourdieu (1988: chap. 4) has described how the growth of the body of university lecturers went along with changing recruitment and career patterns of the profession as a whole. Similar associations may exist if we compare different countries at a given moment in time.

\section{Compositional Effects}

The composition of the labour force can have an impact on aggregate retirement timing in various ways. To begin with, a country's class structure and work-exit pattern are likely to be closely intertwined. One could argue that societies with a high proportion of self-employed and small employers exhibit a high average retirement age, simply because the petty bourgeoisie always retire exceptionally late. In this way, the average retirement age in a country can be influenced by its class structure.

Likewise, women's retirement age in a country can be supposed to depend on the degree of sex-based occupational segregation. Assuming that early retirement is more common in typical female occupations, the average workexit age of women will be higher in a country where the level of occupational segregation is low, such that the class composition among women resembles the male class structure.

If selection effects follow a top-down logic, compositional effects are their bottom-up counterparts. The latter mechanism precisely assumes the absence of the former, i.e. that the overall size of a class does not alter the group-specific work-exit pattern. Unlike institutional filters, compositional or selection effects cannot easily be manipulated by policy makers to achieve a desired change in retirement behaviour. The structural composition of labour markets is deeply rooted in national economic histories, and hence heavily inert (Gerschenkron 1962: chap. 1). 


\section{Cultural Effects}

Culture is, of course, the classical (albeit controversial) answer as to why things are not the same in different countries (cf. Keating 2008). In the previous chapter, we have already introduced the notion of age cultures, which relates to cross-nationally varying retirement attitudes. However, the impact of culture could even be deeper, affecting not only the proportion of people subscribing to age norms favorable of early exit but also the kind of people within a society who subscribe to such norms. Stated in multi-level terminology, it is possible that cultural effects modify not only the intercept but also the slope of a given relationship within each country.

Gender roles are an illustrative matter. To give an example, Crompton and Lyonette (2006) report large differences in sex-specific work attitudes between Britain and Portugal. Whereas respondents' sex and occupational class are strong determinants of attitudes towards job promotion in Britain, this is not the case in Portugal, where no significant differences are found. In this vein, it is plausible that the relationship between gender and retirement behavior is structured differently in diverse national contexts. The analyses in the fourth chapter of this study will test for such gender-specific patterns in retirement attitudes.

Assumptions concerning micro-macro chains have far-going theoretical implications. When relying on a pooled sample using international survey data, particularly within the European Union, it is often implicitly assumed that the underlying social mechanisms work in an identical way. However, in view of ongoing transnationalisation trends, the degree to which this is really the case should be considered an empirical question (Breen \& Rottman 1998). To take up the title of the 2009 conference of the European Sociological Association, are we dealing with "European Society or European Societies?" Specifying how micro-macro linkages play out empirically in Western Europe can help to clarify the extent to which the process of European integration has (as yet) created a society that functions with uniform regularities.

However, the identification of micro-macro mechanisms is a very difficult task. In order to be capable of detecting these micro-macro interactions, "fully specified complex models of the microprocesses" (Mayer 1997: 212) have to be put in comparison. This requirement has to a large extent dictated the choice of data sets exploited in this study. Only micro data that are strictly comparable across countries is drawn upon. Given the trade-off between cross-country and longitudinal information imposed by data availability, the dimension of social change had to be largely left aside as a consequence.

Although the distinction between macro- and micro-level explanatory variables is very useful in heuristic terms, one caveat shall be mentioned here as well: influential processes with respect to retirement timing also take place at 
the meso level of companies, or branches of industry (Jacobs et al. 1991a; Teipen 2003; Ebbinghaus 2006a; Ichino et al. 2007), and would merit investigation in their own right. Yet, due to space restrictions, these issues will not be pursued in detail in the present study. As far as possible, I control for firm-level mechanisms via industry dummy variables.

\subsection{Methodological Foundations}

A main requisite of empirical social research is an analytical toolbox that is adequate in connection with the adopted theory and suits the data at hand. The most eminent problem for assessing retirement ages stems from the disputed definition of the very retirement event. As Smeeding and Quinn point out, the term "retirement" has multiple meanings:

"One would be hard pressed to find a less murky term or one with fewer questions attached. Is retirement defined by labor supply, receipt of retirement income, or by selfdescription? Is it a 'state' behavior or a transitional behavior? [...] And once older workers leave their lifetime jobs do they continue to work? [...] Does receipt of retirement benefits mean total stoppage of work [...]?" (Smeeding \& Quinn 1997: 4)

Against this background, the next sections address potential methodological hitches related to the dependent variable of the present study: the age of retirement. It will be emphasised that multiple pathways into retirement give rise to a plurality of transition modalities, which pose a challenge for every possible definition of the retirement event. I further discuss measurement problems related to retirement ages and include a short review of the common practice in the literature, paying special attention to the much-used retirement-age indicators produced by Eurostat and OECD. An operationalisation of retirement is set out that will be applied in the later chapters. In essence, it refers to late-life labour-force withdrawal.

The final section of this chapter discusses methodological issues related to social class, one of the central explanatory variables in this study. The way to most adequately map social classes within a measurable metric has been subject to a long-standing debate in sociology. Various class schemes compete for scholarly consideration. Therefore, I shall outline the reasons that led to the choosing of the European Socio-economic Classification (ESeC) for the operationalisation of social class. 


\subsubsection{What is Retirement?}

Contemporary retirement is a markedly diffuse phenomenon. Its blurriness is the product of rapid socioeconomic change, which has led to greater disorderliness and plurality in labour market careers. Empirically, today's retirement transitions are far more manifold in terms of timing and sequencing than some decades ago, with this trend producing both conceptual and technical problems for the measurement of retirement ages, particularly in the realm of cross-national comparative research.

Since the expansion of labour-shedding practices in the 1970s, retirement less frequently takes the conventional form of a simple shift from employment to non-employment accompanied by uptake of an old-age pension. Instead, employment exit on the one hand and entrance into the old-age pension scheme on the other have often become separate life events. At the same time, empirical patterns of retirement have become very diverse - within as well as between countries - such that the variance in retirement timing cannot anymore be depicted without reference to the transitory and supplementary use of unemployment benefits, disability pensions, or firm-sponsored retirement plans. In effect, retirement is better understood as a process rather than a onetime event. Correspondingly, the state-of-the-art methodological approach to retirement transitions is dynamic in that it distinguishes between different pathways into retirement (Kohli et al. 1991; Kohli 1993; Flippen 2005; Radl 2006b, 2007; Fasang 2012).

A pathway into retirement consists of a particular sequence of status conditions through which an individual passes when moving from late-career employment to the receiving of an old-age pension. Status conditions are distinguished on the basis of formal employment status and sources of income (Kohli $\&$ Rein 1991). The pathway concept draws on two central notions within the life course paradigm: transition and trajectory (Han \& Moen 1999). Pathways into retirement can also be thought of as institutional bridges for the transition from work to retirement. In fact, for most countries, it is still possible to identify a specific set of typical trajectories for the status passage between work and retirement that represent the great majority of individual retirement transitions (Scherger 2007; Fasang 2012). Social-policy arrangements and firms' retirement plans together provide a certain portfolio of standard routes for the status passage from employment to retirement.

However, not all workers have access to every existing, institutionally defined retirement pathway. Instead, pathways are socially selective, because accessibility depends on various eligibility criteria. For example, qualifying for an old-age pension normally requires a minimum contribution period. For the drawing of a disability pension, it is also necessary to officially have a reduced earning capacity. Sometimes, access to old-age pension benefits 
hinges on previous employment status, e.g. to be unemployed for a certain time before being entitled to early retirement benefits. Employer-sponsored early retirement programmes are likewise usually offered only to a certain fraction of the workforce. In this way, different institutionalised arrangements provided by firms or the state channel different kinds of workers through the status passage from work to retirement. Note that the financial and the normative attractiveness of exit pathways are correlated but do not converge. Particularly, an imposed early exit through redundancy or disability can lead to social stigmatisation and self-accusation in spite of generous economic compensation (Wolf 1988; Riach \& Loretto 2009).

In short, pathways from work to retirement can be simple or sequential and differ considerably with respect to their eligibility, generosity, and control. Pathways into retirement can stretch over time periods of variable length. Eventually, they will differ with regard to subsequent retirement ages. Therefore, the pathway concept is a central heuristic device in the context of this study.

\section{How to Measure Retirement Ages}

The age of retirement may seem an obvious concept. Quite the contrary, the measurement of retirement ages is indeed very complicated. On the one hand, the difficulty of measuring retirement ages is a consequence of the described complexity of empirical retirement processes. On the other hand, and perhaps more importantly, this difficulty arises from ambiguities in the definition of retirement. Specifically, every student of retirement timing faces the problem of identifying the retired population, which involves a twofold identification problem: it requires (a) the fixing of a lower age threshold that delimits which persons shall count as being "eligible" for retirement and (b) the identification of the triggering event that determines the subgroup of the study population that shall count as retired. The former issue has received less attention than the latter, despite being equally important for measuring retirement ages.

A couple of examples shall illustrate the scope of the identification problem. Consider the case of a man or woman who at the age of 42 suffers an accident at work that causes a permanent disability. When shall we count him or her as "retired"? At the time of the accident, or at the time when his or her disability pension gets consecutively converted into an old-age pension (usually at age 65)? Or never, because he or she was too young to retire when he or she left the labour market? Should a married woman or man who dedicated her- or himself to household work during the majortity of her or his adult life automatically count as retired when reaching old age?

(a) The lower age threshold for retirement brings up the question of whether everybody who does not die when still working eventually retires. In principle, 
this boundary could also be drawn using some characteristics other than age, such as the number of years worked. In practice, the adequate approach will depend on the particular research question as well as on data issues and on the definition of the retirement event. The convention is to consider retirement from 50 years of age onwards. For instance, age 50 is the sampling threshold used by the Health and Retirement Study (HRS), the English Longitudinal Study of Ageing (ELSA), and the Survey of Health, Ageing and Retirement in Europe (SHARE). Using a lower minimum age makes it difficult to discern retirement from other forms of inactivity, such as parental leave or sick leave. Without a lower (age) threshold, retirement becomes indistinguishable from other work-exit transitions (e.g. unemployment), which we know are governed by different social mechanisms. Furthermore, persons who were inactive during most of their life (because of ill health or as homemakers) are often excluded from the population of interest because the notion of retirement presupposes prior work. As a matter of fact, the etymological origin of the English word retirement goes back to the French word retirer, which means "to draw back."

(b) As for the defining characteristics of the retirement event, the sociological concept of retirement consists first and foremost in the end of working life, for it is the termination of work that is regarded as the most important biographical milestone in later life (Kohli 1987). From the individual actor's point of view, every-day activities and social status depend heavily on economic activity. Exit from work is correspondingly the most frequent operationalisation of the retirement event. For instance, the first sentence of the Wikipedia entry (13 April 2010) for retirement reads: "Retirement is the point [at which] a person stops employment completely (or decides to leave the labor force if he or she is unemployed)."

An alternative perspective would give priority to the individual's sources of income. In fact, the receipt of an old-age pension benefit is used as constitutive criterion for retirement in some studies (e.g. Fasang 2008; Radl 2008). However, within this definition of the retirement event, it can become a source of confusion that some pathways lead directly into old-age pension schemes whereas others are sequential, stringing various sources of income together (unemployment or disability benefits, special early retirement schemes, firm-sponsored provisions, indemnity pay, etc.). Most importantly, unemployment represents a serious identification problem for an income-based retirement definition. In principle, jobless workers are part of the labour force and thus not retired, because it is supposed that this situation is only a temporary break between employment spells. Yet, unemployment insurance often serves as a bridging device that provides income while waiting for eligibility for an old-age pension. In this case, older unemployed workers do not actively seek employment and are more appropriately treated as retired. A similar caveat applies to persons receiving social assistance or other mean-tested public transfers. In addition, a pension- 
based definition complicates the comparison of retirement transitions across different welfare states that rely on distinct public-private mixes for old-age provision.

\section{Operationalisation of Retirement}

In sum, each retirement definition has its particular advantages and drawbacks. It has become clear from the foregoing sections that retirement processes can hardly be assessed exhaustively within a purely categorical metric. Yet some sort of dichotomous categorisation is required by most statistical models. Therefore, this study defines retirement as definite exit from lifetime employment after age 50. In this way, it embraces the most common conceptualisation of retirement: we consider retirement from age 50 onwards and identify the retirement event as exit from work. Where applicable, workers who have less than ten years of labour market experience are excluded from the sample. For pragmatic reasons, it is furthermore assumed that no labour market participation occurs beyond a certain age, and hence no retirement. As is usual, for pragmatic reasons, retirement will be considered an absorbing event.

In terms of data management, I rely on an identification of retirees that combines the self-assessment of employment status and actual working hours. Formerly employed or self-employed persons are treated as retired if they report their own employment status as "retired," "disabled, or "inactive". All workers who have left their last job and who do not search for a new job are considered retired. Where applicable, the ILO criterion of current working hours is used instead. In order to be part of the population of interest, individuals must have worked for pay at some point after turning 50.

Having delineated who counts as active and who counts as retired, the age of retirement can be used as a dependent variable in large-scale data analysis. Specifically, I will use an event-history framework: retirement-transition rates will be modelled as age-specific estimates of the likelihood of transitions given a variable population at risk. Since retirement ages greatly depend on the exit routes used, a dynamic perspective will be applied throughout the analysis that takes account of diverse transition modalities. That is, retirees are distinguished with regard to specific pathways into retirement, using a competing risks framework.

\section{The Retirement Age Indicators by Eurostat and OECD}

The demand on behalf of policy makers for information on the labour market participation of elderly workers has improved data availability on retirement timing during the last decades. On a yearly basis, cross-national data on 
retirement ages for a large number of countries are provided by Eurostat and OECD. Since these statistics are used on several occasions in the course of this study, they shall be introduced briefly.

The retirement age indicators provided by Eurostat and OECD rely on national labour-force surveys, which are conducted by national statistical offices. However, the international reporting system in the area of labour market statistics is largely restricted to aggregate data. Lacking information on individual employment biographies, the calculated retirement ages have to be regarded as relatively crude approximations. Eurostat and OECD use similar methods in order to estimate retirement ages, and both base these ages upon some rather restrictive socio-demographic assumptions and also raise the wellknown problems of cross-national comparability and data quality.

Until quite recently, it was common practice to measure retirement ages by simply comparing the participation rates of different age groups at one particular moment in time. This static indicator was introduced by Latiluppe (1996) and was explicitly formulated in an oft-cited OECD paper by Blöndal and Scarpetta (1998). As Johnson (2001) and Scherer (2002) demonstrate, this measure has a number of undesirable properties and may convey misguiding information. In essence, it builds on the assumption that age-specific labour market participation remains stable in the relevant period. The method is particularly sensitive to changes in cohort participation rates, which renders its use problematic, especially for assessing female labour supply. The dynamic probability model, which today is the basis for both Eurostat and OECD estimates of retirement ages, is described at length in Scherer (2002). It has the virtue of abandoning the assumption of a completely stationary labour force. Instead, it estimates average retirement ages by comparing artificial cohorts across consecutive surveys, exploiting the linearity of biological aging. More precisely, the age-specific probability of leaving the labour force is calculated on the basis of the change in the difference between the number of active and the number of non-active persons within a particular age bracket. It treats all unemployed persons as non-retired while everybody who works at least one hour per week in paid work counts as employed.

In spite of relying on the same generic concept, there are also noteworthy differences between Eurostat and OECD data on retirement ages. Eurostat considers the exit from the labour market between age 50 and 70 and calculates retirement probabilities for single age groups. In contrast, the OECD uses quinquennial age-groups, imposing the additional assumption of constant hazards, and follows the economic activity of these 5-year clusters in the wider age interval between 40 and 80 years. In sum, the cohort-adjusted retirement-age indicators, which are provided by the international statistical bodies, use appropriate methodology but still rely on strong assumptions concerning changes in the reference population and individual labour market activity. 


\subsubsection{Social Class: Schemes and Controversies}

The concept of social class has been fiercely debated ever since Karl Marx (1969 [1867]) claimed its absoluteness as both objective matter and analytical category in social theory (Mayer \& Carroll 1987; Van Parijs 1987; Goldthorpe \& Marshall 1992; Wright 1997; Grusky \& Sørensen 1998; Goldthorpe 2000: chap. 10; Sørensen 2000, 2001; Scott 2002; Wright 2005; McGovern et al. 2007). It is essential to distinguish between two broad schools of thought in class analysis, namely the Marxist and the Weberian account. Contemporary class analysis largely follows the (neo) Weberian tradition (Breen 2005), according to which classes are defined on the basis of a common market condition (Weber 2005 [1922]: 223 ff.). This "stratum concept of social class" (Sørensen 2001) captures the types of employment relationship and working conditions shared among broad occupational groups. ${ }^{22}$ In this vein, social classes are still the expression of fundamental economic divides, which translate into inequality of life chances and material life conditions. But the definition of class is decoupled from a particular theory of exploitation. Similarly, potential implications for class-graded attitudes, political behaviour, and life styles - not to mention the general course of history - are submitted to further theorising and empirical observation (cf. section 4.2; Grusky \& Sørensen 1998; Svallfors 2006). This approach stands in stark contrast to a structuralist, Marxist conceptualisation (cf. Van Parijs 1987; Wright 1997), in which class structures are inherently tied to identities ("class consciousness") and the direction of macro social development.

In modern class analysis, moreover, the focus has shifted from the dualism between capitalists and the proletariat to structures of stratification within the large group of dependently employed (Goldthorpe 1982). A major part of the discussion has thus been concerned with the most adequate grouping of individuals into homogeneous categories (Scott 2002; Leiulfsrud et al. 2005). Although today's class schemes usually preserve a hierarchical criterion, the increasing weight of service occupations together with the diversification of work and family forms have been mirrored in a differentiation of class typologies.

The most commonly used class schema has been formulated by Erikson and Goldthorpe (1992). The EGP (Erikson-Goldthorpe-Portocarero) schema is based on a typology of employment relationships (Goldthorpe 2000: chap. 10). On the

22 By contrast, a "quasi-Durkheimian" approach (Grusky \& Weeden 2001) calls for a disaggregated approach to class analysis that takes concrete occupations as a starting point (cf. Birkelund 2002; Weeden \& Grusky 2005). 
one hand, self-employment is held separate from dependent employment. On the other hand, the schema draws a distinction between the labour contract and the service relationship. The labour contract consists of a direct exchange of wages for clearly specified amounts of low-skilled labour, which usually takes place on a short-term basis. On the contrary, the service relationship corresponds to jobs with high skill requirements that necessarily involve "an import measure of trust" (Goldthorpe 1982: 168; emphasis in original). Since the typical tasks of managerial, professional, and administrative employees are based on the delegation of authority, they are difficult to supervise. Therefore, employers need to rely to some extent on their employees to abstain from abusing the discretion inherently demanded by their jobs. This is achieved by a long-term commitment, which takes the form of a high employment security and continuous salary increments (ibid.: 169). The introduction of expectations of reciprocity modifies the market character of the employment relationship in fundamental ways. This difference in the nature of the employment relationship is reflected in the distinction between working class and service class.

An additional type is made up by the so-called intermediate occupations that are characterised by a mixed employment relationship. The mix can consist of a low human-asset specificity combined with high costs of supervision - typical in routine, non-manual occupations, such as clerical or secretarial worker - or vice versa, as is the case for higher-grade manual workers and lower technicians. ${ }^{23}$ Furthermore, the EGP schema underpins the hierarchical nature of the occupational structure by incorporating the degree of specificity of human capital; for instance, it distinguishes between upper and lower salariat, and between skilled and unskilled manual workers. ${ }^{24}$ The remaining class categories - the total number varies from seven to eleven in the different formulations - take account of the dissimilar work logic of small proprietors and the selfemployed as well as of the distinct work reality in agriculture.

23 McGovern et al. (2007: chap. 3) demonstrate that the conceptual class schema corresponds quite accurately to the empirical mapping of the respective occupations along the dimensions of skill specificity and difficulty of monitoring. A close empirical association between class position and skill requirements is also found by Tåhlin (2007), who, however, calls into question the theoretical conception of class as linked to employment relations.

$\mathbf{2 4}$ The treatment of the educational dimension in class categories has also been subject to discussion. The standard position is that skills should only count when they are exploited, that is, when they are required for the occupied job. However, Oesch (2006b: 77) suggested to adjust for differences in formal education by re-allocating individuals that are substantially over- or under-qualified for their jobs. Note that in this context, the ISCO-88 Code implicitly incorporates the skill-requirement barrier into the delineation of the occupational structure. 
The EGP schema has been criticised for its narrow focus on the male occupational structure. In fact, the degree of differentiation for typical female occupations is much lower than for typical male occupations (Oesch 2006b: chap. 3). This reproach is connected to another, namely that the EGP schema is outdated given the disproportionate attention paid to manufacturing. In this spirit, another prominent class typology by Esping-Andersen (1993b) posits a divergence between traditional Fordist jobs and the newly emerging postindustrial service jobs. Similarly, Oesch (Oesch 2006a, b) proposes a new class map that differentiates between three work logics (technical, organisational, inter-personal). Critically, by pointing to the peculiar work roles of employees in the educational and health sectors, this schema makes a serious attempt to reflect the feminisation of the labour force. Another strand of the literature attempts to implement a very similar distinction of work logics within the framework of the EGP schema, albeit only with respect to the service class (Güveli et al. 2007). On this basis, Güveli and De Graaf (2007) show that the socalled "socio-cultural specialists" exhibit a markedly strong tendency towards social closure. Focusing at the other end of the occupational hierarchy, Bernardi and Garrido (2008) analyse the emergence of the "new service proletariat" (cf. Esping-Andersen 1993a). In sum, there is a wide variety of class schemes available. Which schema is most appropriate depends on the particular research question as well as on the availability of adequate data (Leiulfsrud et al. 2005).

This study will rely on the European Socio-economic Classification (ESeC) for the operationalisation of social class (Rose $\&$ Harrison 2007). The ESeC is a further development of the EGP. Conceptually, it is likewise based on the typology of employment contracts along the two axes of human-asset specificity and difficulty of monitoring. In this way, it maintains the general distinction between the working class, intermediate occupations, and the service class (as well as the self-employed and small proprietors). One central innovation is cross-national harmonisation, using the international standard classification of occupations ISCO-88 (Com).

Table 3.1, taken from Rose and Harrison (2007), gives an overview of the ESeC classes. ${ }^{25}$ The definition of the service class is practically the same as in the EGP schema. Examples of higher service class occupations are corporate managers, physicians, or judges; large employers are also located here. Typical lower service class occupations are teachers, nurses, journalists, engineering science technicians, or police inspectors. The delineation of the classes of skilled workers

25 Further details can be found on the project website, which provides excellent documentation and hands-on advice for users: < http://www.iser.essex.ac.uk/research/ esec>. 
The European Socio-Economic Classification.

\begin{tabular}{|l|l|l|l|}
\hline & ESEC CLASS & COMMON TERM & EMPLOYMENT REGULATION \\
\hline 1 & $\begin{array}{l}\text { Large employers, higher- } \\
\text { grade professional, } \\
\text { administrative, and } \\
\text { managerial occupations }\end{array}$ & Higher salariat & Service Relationship \\
\hline 2 & $\begin{array}{l}\text { Lower-grade professional, } \\
\text { administrative, and } \\
\text { managerial occupations and } \\
\text { higher-grade technician and } \\
\text { supervisory occupations }\end{array}$ & Lower salariat & Service Relationship \\
\hline 3 & $\begin{array}{l}\text { Intermediate occupations } \\
\text { (modified) }\end{array}$ & $\begin{array}{l}\text { Higher-grade white-collar } \\
\text { workers }\end{array}$ & Mixed \\
\hline 4 & $\begin{array}{l}\text { Small-employer and self- } \\
\text { employed occupations } \\
\text { (except agriculture etc.) }\end{array}$ & $\begin{array}{l}\text { Petite bourgeoisie or } \\
\text { independents }\end{array}$ & Not applicable \\
\hline 5 & $\begin{array}{l}\text { Self-employed occupations } \\
\text { (agriculture etc.) }\end{array}$ & $\begin{array}{l}\text { Petite bourgeoisie or } \\
\text { independents }\end{array}$ & Not applicable \\
\hline 6 & $\begin{array}{l}\text { Lower-supervisory and lower- } \\
\text { technician occupations }\end{array}$ & $\begin{array}{l}\text { Higher-grade blue-collar } \\
\text { workers }\end{array}$ & Mixed \\
\hline 7 & $\begin{array}{l}\text { Lower services, sales, and } \\
\text { clerical occupations }\end{array}$ & $\begin{array}{l}\text { Lower-grade white-collar } \\
\text { workers }\end{array}$ & Labour Contract (modified) \\
\hline 8 & Lower technical occupations & Skilled workers & Laboor Contract (modified) \\
\hline 9 & $\begin{array}{l}\text { Semi- and non-skilled } \\
\text { workers }\end{array}$ & Labour Contract \\
\hline
\end{tabular}

Source: Rose \& Harrison (2007: 464).

as well as higher-grade blue-collar workers is also largely unchanged. Class 8 includes, for instance, machinery mechanics, tool-makers, fitters, plumbers, and locomotive drivers. The occupations in Class 6 are mostly the same as in Classes 7,8 , or 9 , the difference being that their incumbents exercise a supervisory function (foremen). Moreover, lower technicians, such as safety and quality inspectors, telephone line installers, or instrument makers, are placed here.

An important modification with respect to EGP is the creation of Class 7.26 Unlike the intermediate occupations of Class 3 (e.g. office clerks, secretaries, teaching associate professionals), which are characterised by a mixedemployment relation, these lower-grade white-collar workers count as working class. Often, we find here women who work part-time (Rose \& Harrison 2007:

26 Its closest correspondence in EGP would be class IIIb. 
468), for instance, in personal care or client information services, but also as cashiers or shop and market salespeople. The lowest class category, routine occupations, comprises not only non-skilled or semi-skilled manufacturing workers (e.g. machine operators, assemblers) but also lower service jobs (e.g. motor vehicle drivers, porters, domestic helpers, cleaners, housekeeping and restaurant service workers). Finally, the petite bourgeoisie consists of small employers (with less than ten employees) and the self-employed. Among these independent workers a further distinction is made between agricultural (Class 5) and non-agricultural occupations (Class 4).

The ESeC has been chosen for the present study for two main reasons. Firstly, the theoretical account based on the differential nature of the employment contract seems appropriate given the analytical focus on the structure-agency nexus in retirement transitions. It can be assumed that the quality of the employment relationship is crucial for the constraints faced by senior workers. At the same time, the ESeC seems superior to the EGP in the present context because analysing the gender division in retirement is of central concern.

Secondly, this piece of research is genuinely comparative, the universe of analysis being Western Europe. While the EGP is rooted in the British occupational structure of the 1960s, the ESeC has been explicitly designed for a contemporary European context, and the construct has been validated for a number of European countries (e.g. Müller et al. (2007)). A practical advantage of the $\mathrm{ESeC}$ vis-à-vis other schemes, e.g. the one proposed by Oesch, is the fact that the classification is based on the ISCO minor groups (3-digit codes) and not on the more detailed unit groups, for which the full 4-digit codes are required. Tests for operational validity showed that the ESeC is even relatively reliable if only the 2-digit ISCO codes are available (Rose \& Harrison 2007: 474).

In short, the ESeC appears as the most adequate class schema in the context of the present study. Reduced versions of the schema will be applied instead of the full classification where appropriate. Versions are chosen to match sample size and marginal distributions of the respective data sets (cf. table 3.2). For instance, there are many self-employed but few higher-grade blue-collar workers in Spain, whereas in Germany, the constellation is the other way around. The reduced schema is obtained by collapsing the two kinds of self-employed (Classes 4 and 5) and the two groups of intermediate occupations (Classes 3 and 6), respectively.

A point of discussion has been about the proper way of determining the class position of different members of a household in the presence of female employment (Crompton 1989; Sørensen 1994). In the conventional approach, the male breadwinner determines the class position of all household members (Goldthorpe 1983). This account was criticised fiercely by feminist scholars who demanded the labour market status of women be reflected in the class position of the conjugal unit (Stanworth 1984). Since the unit of analysis in the 
Table 3.2

Versions of ESeC Class Schema by Chapter and Data Set.

\begin{tabular}{|l|c|c|c|l|}
\hline ChApter & Topic & DAta Set & No. of CLASSES & Collapsed Classes \\
\hline 4 & Age Norms & ESS & 9 & Full schema \\
\hline 5 & Retirement Patterns & SHARE & 7 & $\begin{array}{l}3+6=\text { Intermediate } \\
4+5=\text { Self-employed }\end{array}$ \\
\hline 6 & Spain & EPA & 8 & $3+6=$ Intermediate \\
\hline 6.5 .4 & $\begin{array}{c}\text { Spain } \\
\text { (Competing Risks } \\
\text { Models) }\end{array}$ & EPA & 6 & $\begin{array}{l}1+2=\text { Salariat } \\
3+6=\text { Intermediate } \\
4+5=\text { Self-employed }\end{array}$ \\
\hline 7 & Germany & Mikrozensus & 8 & $4+5=$ Self-employed \\
\hline
\end{tabular}

Source: own elaboration

present study is the individual rather than the household, we do not here face this problem. It is assumed that not only women's work exit trajectories but also their normative orientations are determined to a larger extent by their own occupation than by their husbands'. In consequence, we determine women's occupational class position in exactly the same way as men's. In any case, since women are typically employed in service jobs, the balance between secondaryand tertiary-sector jobs was an important criterion for electing the ESeC as the class schema to be used throughout this study. 